\title{
Long non-coding RNA SOX2OT promotes cell proliferation and motility in human ovarian cancer
}

\author{
LING HAN $^{1}$, WEI ZHANG ${ }^{1}$, BINGYI ZHANG ${ }^{2}$ and LEYUN ZHAN ${ }^{2}$ \\ ${ }^{1}$ Department of Obstetrics and Gynecology, Renmin Hospital of Wuhan University, Wuhan, Hubei 430072; \\ ${ }^{2}$ Department of Obstetrics and Gynecology, Renmin Hospital of Three Gorges University, Wuhan, Hubei 430070, P.R. China
}

Received January 20, 2016; Accepted November 10, 2016

DOI: $10.3892 /$ etm.2017.5618

\begin{abstract}
Ovarian cancer is one of the most common malignant gynecological cancers. Although conventional chemotherapies have improved the treatment of patients with ovarian cancer, the mortality rate remains high. Hence, it is crucial that the detailed mechanisms that promote ovarian cancer are urgently identified. Therefore, reverse transcription-quantitative polymerase chain reaction was used to reveal the relative transcript levels. Colony formation assay and cell cycle assay were performed in siRNA-treated cells. Transwell assay and western blot assays were also conducted. The results showed that the expression of long non-coding RNA SRY-box 2 overlapping transcript (SOX2OT) was upregulated in clinical ovarian cancer tissues and in cultured ovarian cancer cells (HO-8910 and HO-8910PM). High expression of SOX2OT negatively correlated with the prognosis of patients with ovarian cancer. Knockdown of SOX2OT by specific small interfering RNA against SOX2OT suppressed the colony formation capacity of invasive ovarian cancer cells and resulted in cell cycle arrest in G0/G1 phase. Key cell cycle regulators, cyclin B1 and cell division cycle 25C, were consistently downregulated by the knockdown of SOX2OT. Furthermore, knockdown of SOX2O Tinhibited cell migration, cell invasion and decreased the expression of mesenchymal protein $\mathrm{N}$-cadherin, whereas the expression of epithelial protein E-cadherin was increased in ovarian cancer cells. Overall, SOX2OT expression levels correlated with the prognosis of patients with ovarian cancer, and SOX2OT promoted cell proliferation and motility in ovarian cancer cells. These findings indicated that SOX2OT may serve as a potential therapeutic target in the treatment of ovarian cancer.
\end{abstract}

Correspondence to: Dr Wei Zhang, Department of Obstetrics and Gynecology, Renmin Hospital of Wuhan University, 238 Jiefang Road, Wuhan, Hubei 430072, P.R. China

E-mail: zhangwei4512@sina.com

Key words: long non-coding RNA, SRY-box 2 overlapping transcript, ovarian cancer, proliferation, motility

\section{Introduction}

Ovarian cancer is one of the most lethal gynecological cancers. In 2012, >65,500 females were diagnosed with ovarian cancer, of which half occurred in Europe (1). Unfortunately, 80\% of women suffering from ovarian cancer are diagnosed at an advanced stage, when the cancer cells have already spread into the abdominal cavity or beyond (2). The traditional therapy for ovarian cancer contains neoadjuvant chemotherapy, followed by surgical interval debulking or alternatively, primary surgical debulking with subsequent adjuvant chemotherapy $(3,4)$. However, postoperative complications have no significant impact on overall survival (5-7). In addition, only a few patients have exhibited an acceptable primary cytoreduction rate, and this has been achieved only when the procedures were performed by experienced surgeons with extended training in the techniques $(8,9)$. Thus, there is an urgent need to identify a novel alternative strategy to diagnose and treat patients with ovarian cancer.

SRY-box 2 (SOX2) is a transcription factor of the SRY-related HMG-box family that is indispensable to the maintenance of the self-renewal and pluripotency of undifferentiated stem cells of the embryo $(10,11)$. The SOX 2 gene was mapped to the $3 q 26.3$ locus of the human chromosome (Chr3q26.3). It is embedded into the intronic region of a multi-exon long non-coding RNA (lncRNA) and thereby gives rise to the SOX2 overlapping transcript (SOX2OT), which transcribes in the same orientation with SOX2 $(12,13)$. SOX2OT is an evolutionarily conserved gene that has a high degree of nucleotide identity, with its homologues in mice and other vertebrates (12). The gene does not contain open reading frames, however, it is spliced into several transcripts that are microRNA-like (14). The concurrent expression pattern between IncRNA, SOX2OT and SOX2 in certain types of human cancer and human stem cells indicates the possibility that they may be involved in specific similar signaling pathways and engage in co-regulation, which has been validated by some recent studies (15-17). SOX2OT was postulated to participate in SOX2 transcription, acting as an important enhancer (14). Functionally, the IncRNA, SOX2OT, has a significant role in tumorigenesis. In 2014, Askarian-Amiri et al (15) investigated the regulatory effects of SOX2OT in human breast cancer, and the concordant role of SOX2OT and SOX2 was revealed. Furthermore, this study demonstrated that SOX2OT reduced 
cell proliferation; however, increased breast cancer cell anchorage-independent growth was detected, indicating that SOX2OT functions as a positive regulator of breast cancer. Additionally, an alternative study determined that SOX2OT promoted cell proliferation in human lung cancer HCC827 and SK-MES-1 cells and in hepatocellular carcinoma cells (HepG2 and SMMC-7721) (18). Furthermore, this study identified that the expression level of SOX2OT was negatively correlated with tumor prognosis $(16,18)$. Taken together, these studies are indicative of the critical role of SOX2OT in human tumorigenesis.

In the present study, we aimed to investigate the detailed role of SOX2OT in human ovarian cancer by using clinical cancer tissues and cultured cells. The association of SOX2OT with respect to the outcome of clinical patients with ovarian cancer was assessed. Moreover, specific small interfering RNA (siRNA) against SOX2OT was employed to knockdown the expression of SOX2OT. Cell proliferation and motility were examined upon depletion of SOX2OT by colony formation and Transwell assays, respectively. The findings of the present study suggested that SOX2OT may bean indicator of poor prognosis in ovarian cancer and may also be a potential therapeutic target for ovarian cancer diagnosis and treatment.

\section{Patients and methods}

Patients and tissues. A total of 105 female patients, aged 30-75 years, who were diagnosed with ovarian cancer and subsequently underwent surgeries at the Department of Obstetrics and Gynecology, Renmin Hospital of Wuhan University (Wuhan, China) were included in the present study. All patients were admitted between January 2013 and January 2015 and were not treated with chemotherapy or radiotherapy prior to surgery. Cancerous tissues and matched adjacent non-cancerous tissues were harvested from each patient after surgery. Clinicopathological variables were obtained from medical records held at Renmin Hospital of Wuhan University. This study was approved by the Research Ethics Committee of Renmin Hospital of Wuhan University. All patients demonstrated their full intention to participate in the present study and written informed consent was obtained from each patient or their guardian, if $<18$ years old.

Cell culture and siRNA transfection. Two human ovarian cancer cell lines, HO-8910, and an aggressive cell line, HO-8910PM, were purchased from the Institute of Biochemistry and Cell Biology of the Chinese Academy of Sciences (Shanghai, China). Cell lines were cultured in RPMI 1640 medium supplemented with $10 \%$ fetal bovine serum (FBS; both Gibco; Thermo Fischer Scientific, Inc., Waltham, MA, USA) in a humidified incubator at $37^{\circ} \mathrm{C}$ containing $5 \% \mathrm{CO}_{2}$. Cells were transfected with specific siRNA against SOX2OT (siSOX2OT) using Lipofectamine 2000 (Invitrogen; Thermo Fischer Scientific, Inc., Waltham, MA, USA) according to the manufacturer's instructions. Briefly, cells were seeded into6-well plates and cultured for an additional $24 \mathrm{~h}$. The medium was refreshed with serum-free RPMI 1640 medium, and the siRNA, together with the transfection reagent, were added into each well. A total of $6 \mathrm{~h}$ later, the medium was replaced with normal RPMI 1640 medium supplemented with
$10 \%$ FBS. Cells were harvested for subsequent analysis $48 \mathrm{~h}$ after transfection in order to collect total RNAs or proteins. siRNAs were synthesized by Jieli Biotech Co. Ltd., (Shanghai, China), with the sequences reported previously (18).

Reverse transcription-quantitative polymerase chain reaction $(R T-q P C R)$. Total RNA from human tissues and cultured cells were extracted with TRIzol reagent (Takara Biotechnology Co., Ltd., Dalian, China). Following this, a total of $1 \mu \mathrm{g}$ RNA was reverse transcribed into cDNA using a Reverse Transcription kit at $37^{\circ} \mathrm{C}$ for $30 \mathrm{~min}$ (Takara Biotechnology Co.). A volume of $20 \mu \mathrm{l}$ DNase (Invitrogen; Thermo Fisher Scientific, Inc.) was added to remove the genomic DNA according to the manufacturer's protocol. qPCR was performed using $5 \mu \mathrm{l}$ SYBR-Green reagent (Applied Biosystems; Thermo Fisher Scientific, Inc.), in an ABI 7900 thermocycler in a volume of $10 \mu \mathrm{l}$, which consisted of $1 \mu \mathrm{l}$ cDNA (1:50 dilution) and $2 \mu \mathrm{l}$ each of the forward and reverse primers $(1 \mathrm{mM})$ according to the manufacturer's protocol. Primers were designed as follows (18): SOX2OT forward, 5'-GCTCGTGGCTTAGGA GATTG-3' and reverse, 5'-CTGGCAAAGCATGAGGAA CT-3'; and GAPDH forward, 5'-GTCAACGGATTTGGTCTG TATT-3' and reverse, 5'-AGTCTTCTGGGTGGCAGTGAT-3'. The PCR cycling conditions were as follows: $95^{\circ} \mathrm{C} 5 \mathrm{~min}$ and 45 cycles of $95^{\circ} \mathrm{C}$ for $10 \mathrm{sec}$ and $60^{\circ} \mathrm{C} 30 \mathrm{sec}$. Relative expression of human SOX2OT was normalized to GAPDH and calculated using the $2^{-\Delta \Delta \mathrm{Cq}}$ method (19).

Colony formation assay. HO-8910PMhuman ovarian cancer cells were pre-transfected with two specific siRNAs against SOX2OT and cultured on 12-well plates. Colonies were stained with crystal violet $(0.1 \%)$ on the 10 th day after seeding into the 12 -well plates. Colonies that contained $>50$ cells were counted and the total number of colonies in each group was quantified. The colony formation rate was calculated using the following formula: Colony formation rate=(number of colonies/number of seeded cells) $\times 100 \%$.

Cell cycle analysis. Monolayers of cells were grown in cultural plates in the presence or absence of the siRNA treatment prior to cell cycle analysis. Non-adherent cells were washed and discarded and the attached cells were trypsinized and counted. A total of $10^{6}$ cells were washed with consecutive cold PBS containing $1 \%$ fetal calf serum (FCS) and fixed with ice-cold methanol overnight. Cells were centrifuged at a low-speed $\left(850 \times \mathrm{g}\right.$ at $\left.4^{\circ} \mathrm{C}\right)$ for $5 \mathrm{~min}$, washed in iced PBS containing $3 \%$ FCS and resuspended. Following this, cells were treated with RNase $(100 \mathrm{mg} / \mathrm{ml})$ together with propidium iodide (PI; $100 \mathrm{mg} / \mathrm{ml}$ ) for $30 \mathrm{~min}$. DNA contents were determined by PI fluorescence (BD Biosciences, San Jose, CA, USA). Results were analyzed using ModFit LT (Version 4; Verity Software House Inc., Topsham, ME, USA).

Cell migration and invasion assay. Cell migration and invasion were determined by assessing the capacity of cells to transmigrate to the lower surface of the Transwell chambers (Corning, Inc., Corning, NY, USA; pore size, $8 \mu \mathrm{m}$ ). To assess cell migration capacity, $2 \times 10^{4} \mathrm{HO}-8910 \mathrm{PM}$ cells, with or without siRNA transfection, were suspended in serum-free RPMI 1640 medium and seeded into the upper chamber of 
each well. Subsequently, $600 \mu 1$ of RPMI 1640 culture media supplemented with $10 \%$ FBS was added into the 24-well plates. Care was taken to avoid bubbles. Cells were incubated for a further $24 \mathrm{~h}$, washed with PBS, fixed with methanol and stained with crystal violet $(0.1 \%)$ for $5 \mathrm{~min}$ at room temperature. Images of cells adhered to the lower surface of the chamber were captured (five random fields) and counted under a light microscope (Nikon Corp., Tokyo, Japan; magnification, x200). For the invasion assay, the membranes of each chamber were pre-coated with a layer of Matrigel (BD Biosciences) for $6 \mathrm{~h}$ in a homothermal incubator at $37^{\circ} \mathrm{C}$. Each experiment was performed in triplicate.

Western blot analysis. Proteins from ovarian cancer cells in the presence or absence of siSOX2OT were extracted with NP-40 lysis buffer (Mairybio, Beijing, China) for analysis when cell confluence reached $\sim 90 \%$. Protein concentration was calculated using a BCA protein assay kit (Thermo Fisher Scientific, Inc.). Western blot assays were performed as described previously (16). Equal volumes of $50 \mu \mathrm{g}$ protein were loaded onto each well and separated by $10 \%$ SDS-PAGE. Polyvinylidene fluoride membranes were then used for immunoblotting. The membrane was blocked in 5\% milk for $1 \mathrm{~h}$ at room temperature. Primary antibodies were then incubated at $4{ }^{\circ} \mathrm{C}$ overnight. After washing with Tris buffered saline with Tween-20 4 times for $8 \mathrm{~min}$, the secondary antibodies were incubated at room temperature for $1 \mathrm{~h}$. GAPDH was used as an internal control. Primary antibodies against cyclin B1 (cat. no. ab23053), cell division cycle 25C (Cdc25C; cat. no.. ab32050;), E-cadherin (cat. no. ab1416) and N-cadherin (cat. no. ab76011) were purchased from Abcam (Cambridge, MA, USA) and used at a dilution of 1:1,000. Primary antibody against GAPDH (cat. no. ab8245) and secondary antibody (conjugated to horseradish peroxidase; cat. no. ab6728) were obtained from Abcam and used at a dilution of 1:1,000. Immunoreactivity was determined by enhanced chemiluminescent autoradiography using an ImageQuant Las4000 (Thermo Fisher Scientific, Inc.).

Statistical analysis. All data were presented as mean \pm standard deviation. Student's t-test was used to compare the difference between controls and the experimental group. Spearman correlation analysis was employed to assess the association between SOX2OT expression and clinicopathological parameters. $\mathrm{P}<0.05$ was considered to indicate a statistically significant difference. Each experiment was repeated in triplicate.

\section{Results}

IncRNA SOX2OT upregulates and associates with multiple factors in human ovarian cancer. The expression of lncRNA SOX2OT was examined in 105 ovarian cancer tissues and their adjacent non-cancerous tissues by RT-qPCR. Fig. 1A demonstrated that the transcript level of SOX2OT was significantly increased by $50 \%$ in ovarian cancer tissues compared with non-cancerous adjacent tissues $(\mathrm{P}<0.05)$. Furthermore, two ovarian cancer cell lines were chosen for subsequent analysis. HO-8910PM is the derivative cell line of HO-8910 with extremely higher invasion abilities (20). The relative transcript level of SOX2OT was significantly higher in HO-8910PM cells when compared with HO-8910 cells $(\mathrm{P}<0.05$; Fig. 1B).
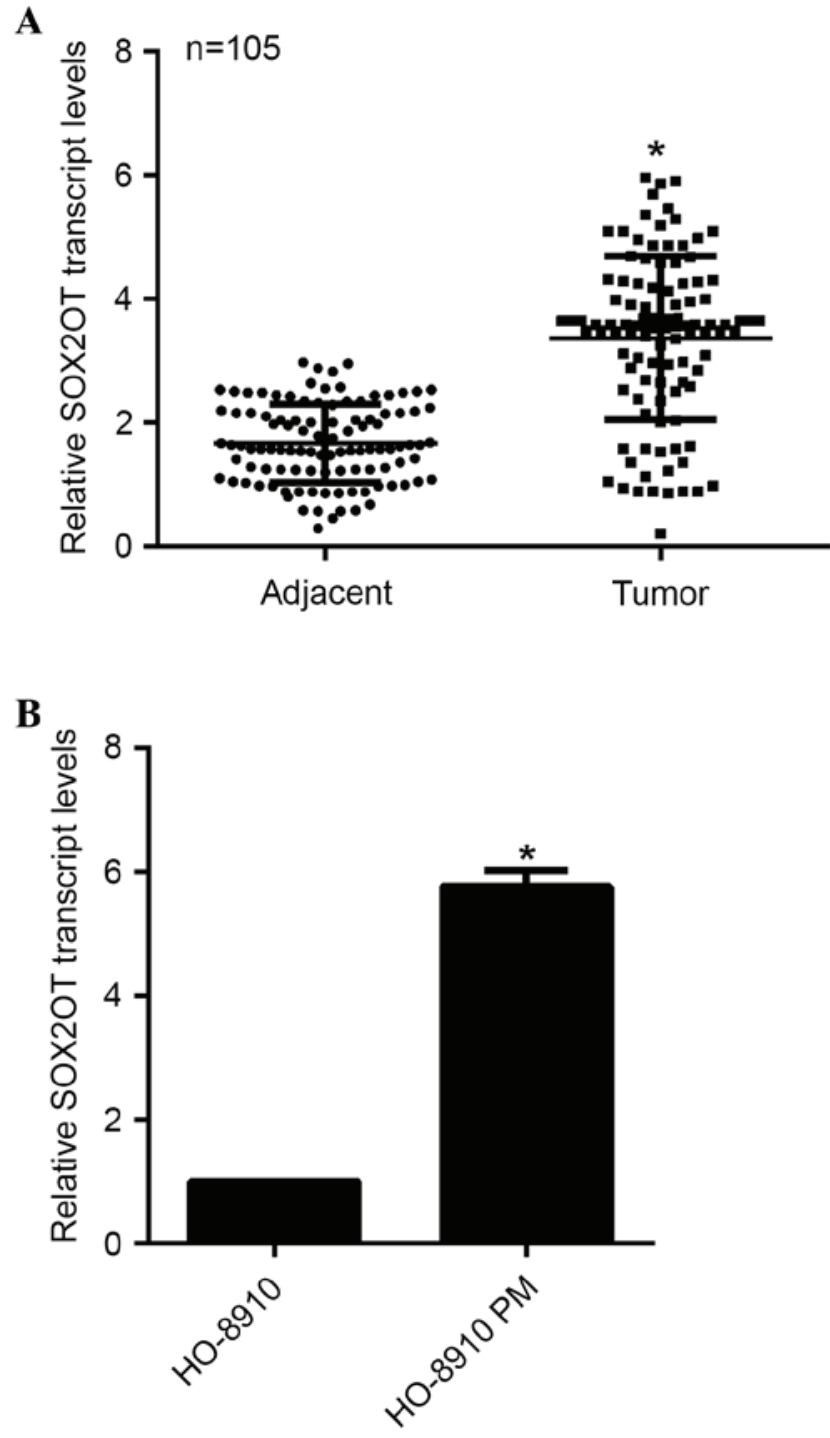

Figure 1. Long non-coding RNA SOX2OT is upregulated in human ovarian cancer. (A) Relative transcript levels of SOX2OT were determined in 105 ovarian cancer tissues and their adjacent non-cancerous tissues. The cases where SOX2OT levels were higher than the median level were regarded as SOX2OT high expression, while those under the median level were considered as exhibiting low expression. " $\mathrm{P}<0.05$, Tumor vs. Adjacent. (B) Relative transcript levels of SOX2OT in cultured ovarian cancer cells, HO-8910 and HO-8910PM. HO-8910PM cell line was highly invasive compared with HO-8910. Data are presented as the mean + standard deviation, error bar not visible. ${ }^{*} \mathrm{P}<0.05, \mathrm{HO}-8910 \mathrm{PM}$ vs. HO-8910. SOX2OT, SRY-box 2 overlapping transcript.

The expression levels of SOX2OT were grouped as high or low in the clinical tissues. The median level of SOX2OT in the clinical tissues was used as a cut-off to differentiate between high expression (over the median level) and low expression (less than the median level). The 105 patients with ovarian cancer were categorized into two groups: 60 cases with relatively high SOX2OT expression and 45 with relatively low SOX2OT expression. Statistical analysis revealed that high expression of SOX2OT positively correlated with age of onset $\left(\mathrm{P}<0.001, \mathrm{r}^{2}=0.466\right)$, tumor size $\left(\mathrm{P}<0.0001, \mathrm{r}^{2}=0.363\right)$, higher TNM stages $\left(\mathrm{P}<0.0001, \mathrm{r}^{2}=0.466\right)$ and lymphatic metastasis $\left(\mathrm{P}<0.0001, \mathrm{r}^{2}=0.451\right.$; Table I). However, no significant correlation was observed between the expression of SOX2OT and 
Table I. Association of the expression of SOX2OT with clinicopathological features in 105 patients with ovarian cancer.

\begin{tabular}{|c|c|c|c|c|c|c|}
\hline \multirow[b]{2}{*}{ Parameters } & \multirow[b]{2}{*}{ Group } & \multirow[b]{2}{*}{ Total } & \multicolumn{2}{|c|}{$\begin{array}{l}\text { Expression of } \\
\text { SOX2OT }\end{array}$} & \multirow[b]{2}{*}{ P-value } & \multirow[b]{2}{*}{$r^{2}$} \\
\hline & & & Low & High & & \\
\hline \multirow[t]{3}{*}{ Age (years) } & $<44$ & 36 & 23 & 13 & 0.0012 & 0.316 \\
\hline & $45-65$ & 63 & 21 & 42 & & \\
\hline & $\geq 65$ & 6 & 1 & 5 & & \\
\hline \multirow[t]{2}{*}{ Tumor size $(\mathrm{cm})$} & $<2$ & 29 & 19 & 10 & $<0.0001$ & 0.363 \\
\hline & $\geq 2$ & 76 & 20 & 56 & & \\
\hline \multirow[t]{2}{*}{ Familial status } & Sporadic & 80 & 41 & 39 & 0.3313 & 0.096 \\
\hline & Familial & 25 & 10 & 15 & & \\
\hline \multirow[t]{2}{*}{ TNM stage } & I-II & 42 & 29 & 13 & $<0.0001$ & 0.466 \\
\hline & III-IV & 63 & 14 & 49 & & \\
\hline \multirow[t]{2}{*}{ Lymphocytic metastasis } & Absence & 41 & 29 & 12 & $<0.0001$ & 0.451 \\
\hline & Presence & 64 & 16 & 48 & & \\
\hline
\end{tabular}

SOX2OT, SRY-box 2 overlapping transcript.

familial status in patients with ovarian cancer. These results suggested that the abnormal expression of lncRNA SOX2OT maybe associated with ovarian cancer progression.

Knockdown of SOX2OT inhibits cell proliferation by arresting the cell cycle in G0/G1 phase. The detailed role of SOX2OT in human ovarian cancer was explored. Two specific siRNAs against SOX2OT (siSOX2OT-1 and siSOX2OT-2) were examined to elucidate the effects of SOX2OT knockdown on the proliferation of HO-8910PM cells. When HO-8910PM cells were transfected with siRNAs, the relative expression of SOX2OT was significantly decreased, suggesting the high transfection efficiency of synthesized siRNA ( $<<0.05$; Fig. 2A). Colony formation assay was subsequently performed in the presence or absence of siRNA. It was demonstrated that both siRNA were able to significantly suppress the colony formation capacity of HO-8910PM cells by up to $50 \%$ ( $\mathrm{P}<0.05$; Fig. $2 \mathrm{~B}$ ). Cell cycle analysis indicated that $>15 \%$ of cells were arrested in G0/G1 phase when SOX2OT was knocked down with both siRNAs in HO-8910PM cells; meanwhile, the percentage of cells in $\mathrm{S}$ and $\mathrm{G} 2 / \mathrm{M}$ phases decreased significantly $(\mathrm{P}<0.05$; Fig. 2C). These data suggested that knockdown of SOX2OT with specific siRNA inhibited colony formation ability by arresting the cell cycle in G0/G1 phase in HO-8910PM ovarian cancer cells.

Knockdown of SOX2OT inhibits cell migration and invasion in ovarian cancer cells. Since the expression of SOX2OT correlated with the aggressive parameters in patients with ovarian cancer (Table I), the role of SOX2OT in cell migration and invasion in vitro was subsequently investigated. The data suggested that the number of cells that migrated through the chamber and adhered to the lower surface of the membrane significantly decreased from 480 to 220 upon transfection of siSOX2OT-1 $(\mathrm{P}<0.05)$. The reduction in the number of cells was greater when cells were treated with the second siRNA (siSOX2OT-2; Fig. 3A). In the cell invasion assay, similar results were observed in HO-8910PM cells. The number of cells that invaded through the Matrigel significantly decreased by $>50 \%$ when SOX2OT was knocked down with either of the two siRNA $(\mathrm{P}<0.05$; Fig. $3 \mathrm{~B})$. These data suggested that SOX2OT positively regulated cell motility in human ovarian cancer cells.

Knockdown of SOX2OT decreases cell cycle regulators and interrupts the epithelial-mesenchymal transition (EMT). Based on the aforementioned observations, key cell cycle regulators (cyclin B1 and Cdc25C) and EMT markers (mesenchymal N-cadherin and epithelial E-cadherin) were detected in HO-8910PM cells following transfection with siSOX2OT. EMT is a process by which epithelial cells lose their cell-cell adhesion and polarity and gain their migratory and invasive properties to form mesenchymal stem cells. This process has a significant role in the initiation of metastasis for cancer progression (20,21). Fig. 4 demonstrated that when SOX2OT was knocked down by specific siRNA, the protein levels of cyclin B1, Cdc25C and N-cadherin were all decreased, whereas the protein level of E-cadherin was increased after knockdown of SOX2OT. These results were consistent with our previous observations in this study.

\section{Discussion}

Ovarian cancer is the third most common cancer of the female reproductive system and the majority of patients with ovarian cancer are between the ages of $45-65$ years $(22,23)$. This was also true in the present study, which demonstrated that $63 / 105$ $(60 \%)$ patients with ovarian cancer were between the ages of 45 and 65 years. Moreover, it was observed that the expression of SOX2OT was significantly positively correlated with patient age, TNM staging, tumor size and lymphocytic metastasis. In fact, the increased transcription level of SOX2OT in the invasive HO-8910PM cells compared with HO-8910 cells also indicated that SOX2OT may function as a biomarker 

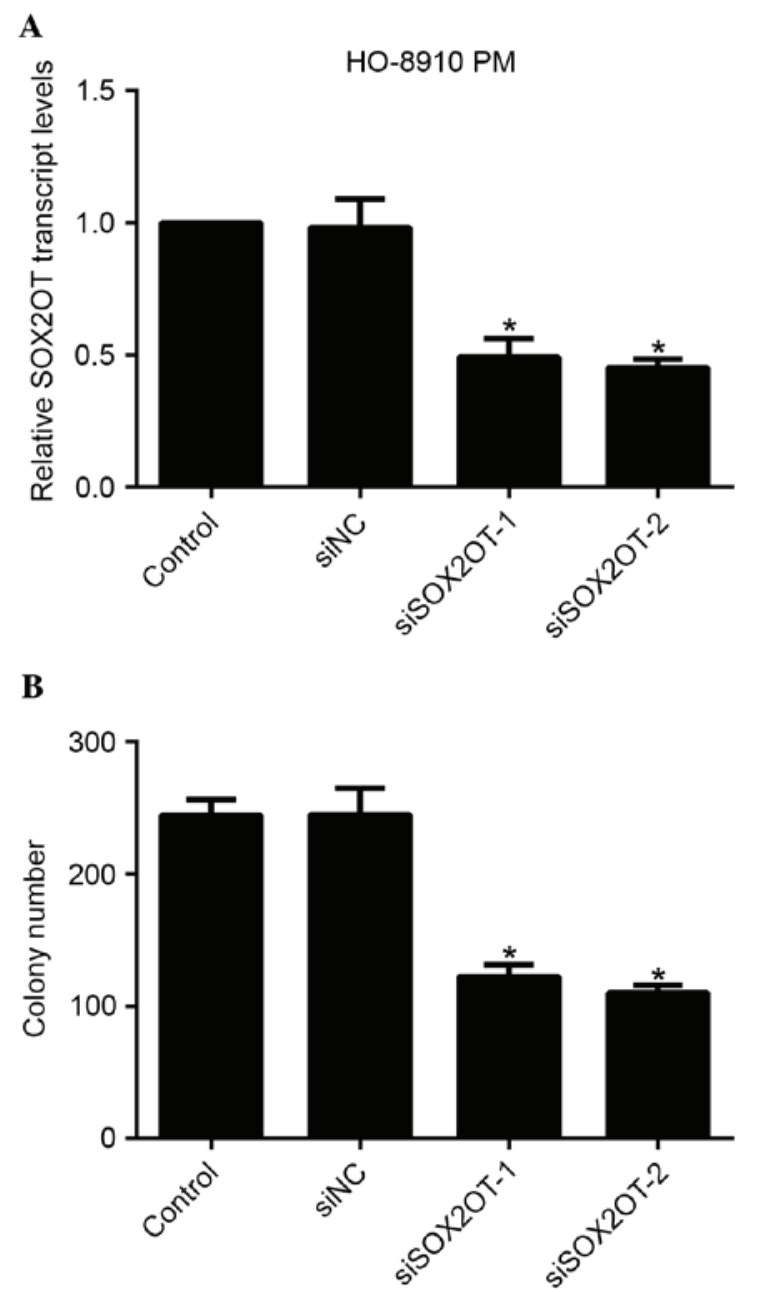

C

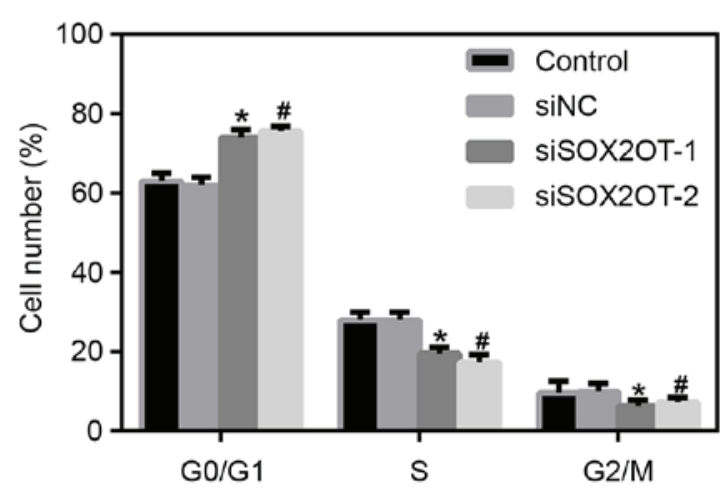

Figure 2. Knockdown of SOX2OT inhibits cell proliferation by arresting the cell cycle in G0/G1 phase. (A) SOX2OT knockdown was achieved using specific siRNAs and the relative SOX2OT transcript levels were determined by reverse transcription-quantitative polymerase chain reaction. (B) The colony formation assay indicated that the number of colonies formed decreased upon si SOX2OT transfection. " $\mathrm{P}<0.05$ vs. controls. (C) The percentage of cells in each phase of cell cycle was analyzed when HO-8910PM cells were transfected with specific siRNAs against SOX2OT (siSOX2OT). Data are presented as the mean \pm standard deviation, error bar not visible. ${ }^{*} \mathrm{P}<0.05$, siSOX2OT-1 vs. controls; ${ }^{\prime} \mathrm{P}<0.05$, siSOX2OT-2 vs. controls. SOX2OT, SRY-box 2 overlapping transcript; siNC, small interfering normal control.

by indicating the aggressiveness of ovarian cancer. These analyses suggested that the expression of SOX2OT was positively correlated with the aggressive characteristics in ovarian

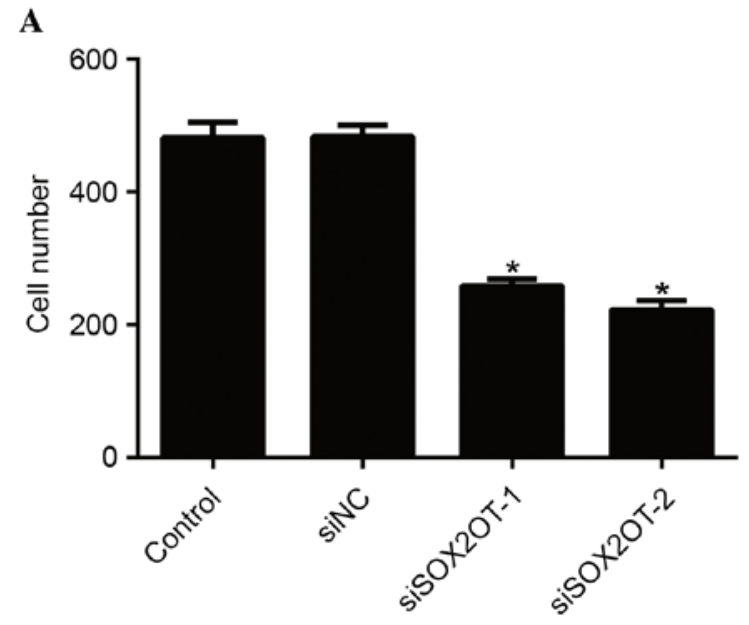

B

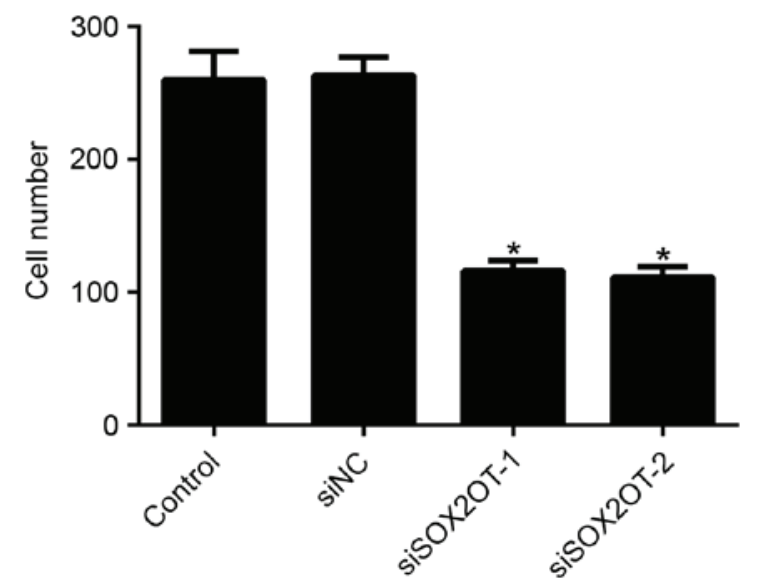

Figure 3. Knockdown of SOX2OT inhibits cell migration and invasion in ovarian cancer cells. (A) Cell migration assay demonstrated that knockdown of SOX2OT inhibited cell migration abilities in HO-8910PM cells. (B) Cell invasion assay showed that knockdown of SOX2OT inhibited cell invasion capacities in cultured ovarian cancer cells. Cell numbers were calculated from randomized five fields. Data are presented as the mean \pm standard deviation. "P<0.05 vs. control. SOX2OT, SRY-box 2 overlapping transcript; siNC, small interfering normal control.

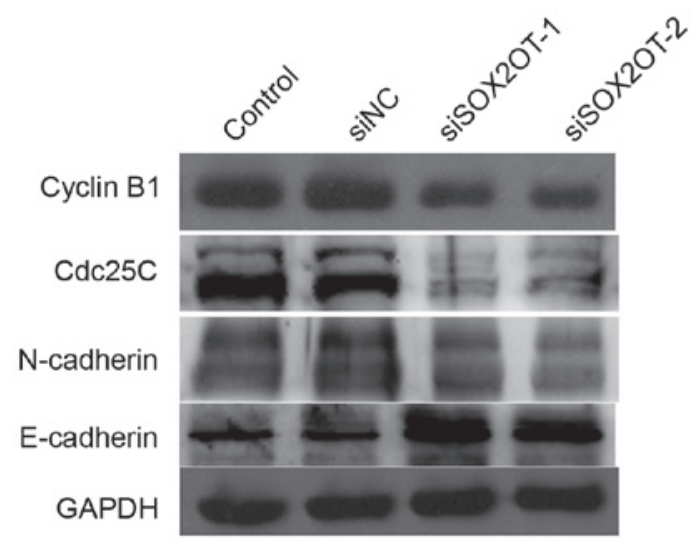

Figure 4. Knockdown of SOX2OT decreases the key cell cycle regulators and interrupts the epithelial-mesenchymal transition process. Western blot analysis revealed that knockdown of SOX2OT suppressed the expression of key cell cycle regulators, cyclinB1 and $\mathrm{Cdc} 25 \mathrm{C}$. The epithelial marker (E-cadherin) was increased, while the mesenchymal marker (N-cadherin) was decreased by knockdown of SOX2OT in HO-8910PM cells. SOX2OT, SRY-box 2 overlapping transcript; siNC, small interfering normal control; Cdc25C, cell division cycle 25C. 
cancer. Ovarian cancer in patients at an older age (45-65 years) potentially exhibits a higher expression of SOX2OT.

Knockdown of SOX2OT in human HO-8910PM cells inhibited cell proliferation, which was demonstrated by the colony formation assay. Furthermore, depletion of SOX2OT arrested the cell cycle in G0/G1 phase, which was indicated by decreases in the percentage of cells in $\mathrm{S}$ phase and $\mathrm{G} 2 / \mathrm{M}$ phase. Hou et al (16) reported that knockdown of SOX2OT inhibited the proliferation of lung cancer cells by inducing G2/M arrest. Another report by Shahryari et al (17) suggested that knockdown of SOX2OT caused preferable cell distribution in G1 and sub-G1 phases in esophageal squamous cell carcinoma, which was consistent with our results. These findings suggest that SOX2OT may inhibit cell proliferation by arresting cell cycle progression in certain tumor types. Despite the disparity, these studies were consistent in considering that SOX2OT inhibited cell proliferation by arresting cell cycle progression. Interrupted cell cycle progression was also evidenced by the dysregulation of key cell cycle regulators, cyclin $\mathrm{B} 1$ and $\mathrm{Cdc} 25 \mathrm{C}$. Cyclin $\mathrm{B} 1$ is a regulatory protein involved in the process of mitosis (17). Cdc25C protein participates to control the entry of cells into different phases during cell cycle progression in mitosis (24). The decreased expression of cyclinB1 and $\mathrm{Cdc} 25 \mathrm{C}$ indicated in the present study strengthens our conclusion that SOX2OT positively regulates tumor growth in ovarian cancer.

EMTs are critical in the manifestation of epithelial cell plasticity, in which multiple regulatory molecules are involved, including the Zeb family and the Snail family (25). The EMT process is regulated by various cellular procedures, including increased expression of mesenchymal markers ( $\mathrm{N}$-cadherin and vimentin), decreased protein levels of epithelial markers (E-cadherin), overexpression of extracellular matrix compounds (Fibronectin), and altered localization of specific transcription factors (Snail) and activation of kinases (phosphoinositide 3-kinase/Akt) (22). Ovarian cancer is considered to be a 'silent killer' since the majority of patients with ovarian cancer are asymptomatic until the tumor has metastasized, therefore, patients are usually diagnosed at an advanced stage (26). During cancer development, cancer cells may acquire invasive abilities. A particular route that promotes cancer progression and metastasis involves alterations in vital components associated with EMT programming, which may result in the optimal microenvironment for ovarian cancer cells. Previous studies have demonstrated that EMT activation in ovarian cancer is associated with chemoresistance, which may instigate cancer recurrence and metastasis after traditional treatment $(27,28)$. Therefore, the EMT process may be considered as a potential target for the diagnosis and treatment of ovarian cancer.

The present study indicated that expression of SOX2OT was associated with tumor staging and the lymphocytic metastasis in the clinical analysis. In the cell migration and invasion assays in vitro, knockdown of SOX2OT in HO-8910PM cells suppressed cell motility significantly. Notably, the epithelial marker (E-cadherin) was increased, while the mesenchymal marker (N-cadherin) was decreased by knockdown of SOX2OT. The impact of SOX2OT expression on EMT has been reported previously $(15,16,18)$. EMT and its reverse process, mesenchymal-epithelial transition are both critical for embryonic development (21). Epithelial and mesenchymal cells have different phenotypes and functions. Epithelial cells express high level of E-cadherin, while the proteins including $\mathrm{N}$-cadherin, fibronectin and vimentin are overexpressed in mesenchymal cells $(29,30)$. During cancer progression, the transition of epithelial cells into mesenchymal cells is always observed. The present study demonstrated that when SOX2OT was knocked down, the epithelial marker was increased and the mesenchymal marker was decreased in HO-8910PM cells. Morphological changes were also observed. SOX2OT-depleted cells were closely connected to each other, bound by a basal lamina at their basal surface, and exhibited apico-basal polarity. In contrast, the control ovarian cancer cells lacked this polarization, had spindle-shaped morphology and interacted with each other only through focal points (data not shown). All these observations indicated that SOX2OT was able to transition tumor cells to more aggressive ones.

In conclusion, the present study demonstrated that lncRNA SOX2OT was positively associated with aggressiveness in ovarian cancer, including tumor size, TNM stages and lymphocytic metastasis. Knockdown of SOX2OT inhibited cell proliferation and motilities in cultured ovarian cancer cells. These functions may be achieved by arresting cell cycle and promoting EMT processes. Our findings provide strong evidence that SOX2OT may be a potential therapeutic target against human ovarian cancer.

\section{References}

1. Ferlay J, Steliarova-Foucher E, Lortet-Tieulent J, Rosso S, Coebergh JW, Comber H, Forman D and Bray F: Cancer incidence and mortality patterns in Europe: Estimates for 40 countries in 2012. Eur J Cancer 49: 1374-1403, 2013.

2. Stuart GC, Kitchener H, Bacon M, DuBois A, Friedlander M, Ledermann J, Marth C, Thigpen T and Trimble E; participants of 4th Ovarian Cancer Consensus Conference (OCCC); Gynecologic Cancer Intergroup: 2010 Gynecologic Cancer InterGroup (GCIG) consensus statement on clinical trials in ovarian cancer: Report from the fourth ovarian cancer consensus conference. Int J Gynecol Cancer 21: 750-755, 2011.

3. Vergote I, Amant F, Kristensen G, Ehlen T, Reed NS and Casado A: Primary surgery or neoadjuvant chemotherapy followed by interval debulking surgery in advanced ovarian cancer. Eur J Cancer 47 (Suppl 3): S88-S92. 2011.

4. Vergote I, Tropé CG, Amant F, Kristensen GB, Ehlen T, Johnson N, Verheijen RH, van der Burg ME, Lacave AJ, Panici PB, et al: Neoadjuvant chemotherapy or primary surgery in stage IIIC or IV ovarian cancer. N Engl J Med 363: 943-953, 2010.

5. Landrum LM, Java J, Mathews CA, Lanneau GS Jr, Copeland LJ, Armstrong DK and Walker JL: Prognostic factors for stage III epithelial ovarian cancer treated with intraperitoneal chemotherapy: A gynecologic oncology group study. Gynecol Oncol 130: 12-18, 2013.

6. du Bois A, Reuss A, Pujade-Lauraine E, Harter P, Ray-Coquard I and Pfisterer J: Role of surgical outcome as prognostic factor in advanced epithelial ovarian cancer: A combined exploratory analysis of 3 prospectively randomized phase 3 multicenter trials: By the Arbeitsgemeinschaft Gynaekologische Onkologie Studiengruppe Ovarialkarzinom (AGO-OVAR) and the Groupe d'Investigateurs Nationaux pour les Etudes des Cancers del'Ovaire (GINECO). Cancer 115: 1234-1244, 2009.

7. Bookman MA, Brady MF, McGuire WP, Harper PG, Alberts DS, Friedlander M, Colombo N, Fowler JM, Argenta PA, De Geest $\mathrm{K}$, et al: Evaluation of new platinum-based treatment regimens in advanced-stage ovarian cancer: A Phase III Trial of the gynecologic cancer intergroup. J Clin Oncol 27: 1419-1425, 2009.

8. ChiDS,EisenhauerEL,Lang J,Huh J,Haddad L, Abu-Rustum NR, Sonoda Y, Levine DA, Hensley M and Barakat RR: What is the optimal goal of primary cytoreductive surgery for bulky stage IIIC epithelial ovarian carcinoma (EOC)? Gynecol Oncol 103: 559-564, 2006. 
9. Aletti GD, Dowdy SC, Podratz KC and Cliby WA: Surgical treatment of diaphragm disease correlates with improved survival in optimally debulked advanced stage ovarian cancer. Gynecol Oncol 100: 283-287, 2006.

10. Avilion AA, Nicolis SK, Pevny LH, Perez L, Vivian N and Lovell-Badge R: Multipotent cell lineages in early mouse development depend on SOX2 function. Genes Dev 17: 126-140, 2003.

11. Fong H, Hohenstein KA and Donovan PJ: Regulation of self-renewal and pluripotency by Sox 2 in human embryonic stem cells. Stem Cells 26: 1931-1938, 2008.

12. Fantes J, Ragge NK, Lynch SA, McGill NI, Collin JR, Howard-Peebles PN, Hayward C, Vivian AJ, Williamson K, van Heyningen V and FitzPatrick DR: Mutations in SOX2 cause anophthalmia. Nat Genet 33: 461-463, 2003.

13. Williamson KA, Hever AM, Rainger J, Rogers RC, Magee A, Fiedler Z, Keng WT, Sharkey FH, McGill N, Hill CJ, et al: Mutations in SOX2 cause anophthalmia-esophageal-genital (AEG) syndrome. Hum Mol Genet 15: 1413-1422, 2006.

14. Amaral PP, Neyt C, Wilkins SJ, Askarian-Amiri ME, Sunkin SM Perkins AC and Mattick JS: Complex architecture and regulated expression of the Sox 2 ot locus during vertebrate development RNA 15: 2013-2027, 2009.

15. Askarian-Amiri ME, Seyfoddin V, Smart CE, Wang J, Kim JE, Hansji H, Baguley BC, Finlay GJ and Leung EY: Emerging role of long non-coding RNA SOX2OT in SOX2 regulation in breast cancer. PLoS One 9: e102140, 2014.

16. Hou Z, Zhao W, Zhou J, Shen L, Zhan P, Xu C, Chang C, Bi H, Zou J, Yao X, et al: A long noncoding RNA Sox2ot regulates lung cancer cell proliferation and is a prognostic indicator of poor survival. Int J Biochem Cell Biol 53: 380-388, 2014.

17. Shahryari A, Rafiee MR, Fouani Y, Oliae NA, Samaei NM, Shafiee M, Semnani S, Vasei M and Mowla SJ: Two novel splice variants of SOX2OT, SOX2OT-S1, and SOX2OT-S2 are coupregulated with SOX2 and OCT4 in esophageal squamous cell carcinoma. Stem Cells 32: 126-134, 2014.

18. Shi XM and Teng F: Up-regulation of long non-coding RNA Sox 2ot promotes hepatocellular carcinoma cell metastasis and correlates with poor prognosis. Int J Clin Exp Pathol 8: 4008-4014, 2015.

19. Livak KJ and Schmittgen TD: Analysis of relative gene expression data using real-time quantitative PCR and the 2(-Delta Delta C(T)) method. Methods 25: 402-408, 2001.
20. Su D, Katsaros D, Xu S, Xu H, Gao Y, Biglia N, Feng J, Ying L, Zhang P, Benedetto C and Yu H: ADP-ribosylation factor-like 4C (ARL4C), a novel ovarian cancer metastasis suppressor, identified by integrated genomics. Am J Transl Res 7: 242-256, 2015.

21. Morata-Tarifa C, Jiménez G, Garcia M, Entrena JM, Griñán-Lisón C, Aguilera M,Picon-Ruiz M and Marchal JA: Low adherent cancer cell subpopulations are enriched in tumorigenic and metastatic epithelial-to-mesenchymal transition-induced cancer stem-like cells. Sci Rep 6: 18772, 2016.

22. Thiery JP, Acloque H, Huang RY and Nieto MA: Epithelial-mesenchymal transitions in development and disease. Cell 139: 871-890, 2009.

23. Salehi F, Dunfield L, Phillips KP, Krewski D and Vanderhyden BC: Risk factors for ovarian cancer: An overview with emphasis on hormonal factors. J Toxicol Environ Health B Crit Rev 11: 301-321, 2008.

24. Zhan Q, Antinore MJ, Wang XW, Carrier F, Smith ML, Harris CC and Fornace AJ Jr: Association with Cde2 and inhibition of $\mathrm{Cdc} 2 / \mathrm{Cyclin} \mathrm{B} 1$ kinase activity by the p53-regulated protein Gadd45. Oncogene 18: 2892-2900, 1999.

25. Sartor H, Ehlert F, Grzeschik KH, Müller R and Adolph S: Assignment of two human cell cycle genes, CDC25C and CCNB1, to $5 \mathrm{q} 31$ and 5q12, respectively. Genomics 13: 911-912, 1992.

26. Strauss R, Li ZY, Liu Y, Beyer I, Persson J, Sova P, Möller T, Pesonen S, Hemminki A, Hamerlik P, et al: Analysis of epithelial and mesenchymal markers in ovarian cancer reveals phenotypic heterogeneity and plasticity. PLoS One 6: e16186, 2011.

27. Holschneider $\mathrm{CH}$ and Berek JS: Ovarian cancer: Epidemiology, biology and prognostic factors. Semin Surg Oncol 19: 3-10, 2000.

28. Abdullah LN and Chow EK: Mechanisms of chemoresistance in cancer stem cells. ClinTransl Med 2: 3, 2013 .

29. Iwatsuki M, Mimori K, Yokobori T, Ishi H, Beppu T, Nakamori S, Baba $\mathrm{H}$ and Mori M: Epithelial-mesenchymal transition in cancer development and its clinical significance. Cancer Sci 101: 293-299, 2010.

30. Thiery JP and Sleeman JP: Complex networks orchestrate epithelial-mesenchymal transitions. Nat Rev Mol Cell Biol 7: 131-142, 2006. 